J. Linguistics 33 (1997), 255-274. Printed in the United Kingdom

(C) 1997 Cambridge University Press

\title{
Forms of address and terms of reference ${ }^{1}$ ELEANOR DICKEY \\ University of Ottawa
}

(Received 2I December I995; revised Io December 1996)

This paper examines the relationship between the use of names and other words in address and in reference: how does the way that speaker $\mathrm{A}$ addresses $\mathrm{B}$ differ from the way that A refers to B, and what are the factors affecting this difference? The study, based on observation and interviews, attempts both to solve a problem in pragmatics and to help historical linguists and others who need to know the extent to which it may be justified to extrapolate from referential to address usage and vice versa.

\section{BACKGROUND}

In recent years much sociolinguistic work has been done on forms of address, following the principles developed by Brown \& Gilman (I960). Most of this work, like Brown and Gilman's original study, has concentrated on the use of address pronouns and $\mathrm{T} / \mathrm{V}$ distinctions. Almost from the beginning of address research, however, a substantial minority of work has been dedicated to the use of nominal address forms (for example, Brown \& Ford I96I). Nominal forms are the only type of address available for study in languages like English which lack (at least in most dialects) a distinction in address pronouns.

One of the most basic points made by researchers investigating nominal address forms is that the social meaning of a word when used as an address does not necessarily have a close connection to that word's literal meaning (Braun I988: 264-265). This fact is essential for explaining how addresses work, for in some languages terms which have derogatory literal meanings function as forms of address with positive social meanings, and it is also possible for addresses to be much less complimentary than one might expect from their literal meanings (Braun I988: 254-255). Moreover, some words are virtually unusable as addresses (for example, gas-station attendant), while others appear only as addresses (for example, sir; Zwicky (1974: 790)).

\section{I Terminology}

Attempts to explain this difference, however, rapidly become entangled in the question of how to define 'meaning' when used of an address. It is argued

[I] I am extremely grateful to David Allerton, Peter Trudgill, Paul Friedrich, Peter Matthews and Anna Morpurgo Davies for their help with this paper. 


\section{ELEANOR DICKEY}

(Braun I988: 255-258) that since the idea that the meaning of a word is to be equated with its referent makes nonsense of addresses like sir and you, students of address usage must adhere to the other option for defining meaning, namely that meaning must be determined by usage. Yet the usage of a word will include its usage as an address, and so a difference between social and literal meaning will be impossible, given that the social is part of the literal meaning. One solution is to exclude arbitrarily the social usage from the usage which defines the literal meaning, but even its proponents find this solution somewhat unsatisfactory (Braun I988: 255).

There is however another option: the replacement of the terms 'literal' and 'social' with 'lexical', 'referential' and 'address', the address meaning of a word to be determined by its usage as an address, the referential meaning by its usage when referring to people or things (that is, in non-address contexts), and the lexical meaning to include both of these. The term 'lexical meaning' is used by Braun (I988: 264) as a synonym for 'literal meaning'.

The most important advantage of such terminology would be the ability it gives us to discuss words with meanings which are primarily 'social' rather than 'lexical', even when these words are not used as addresses. Chief among such words in English are the various forms of a person's name: Jane Smith can be referred to as Jane or as Mrs. Smith (among other things), but the choice between these two alternatives will be socially rather than lexically determined, just as the choice between addressing the same woman as Jane or as Mrs. Smith is socially determined.

The difference in meaning with which sociolinguists studying addresses are concerned is thus a difference between referential and address meanings. Madam in its referential meaning can be used to designate a brothel-keeper, while it is polite in its address meaning. Love in its referential meaning is used of a strong emotion or a person towards whom such strong emotion is felt, but it can be a neutral form of address in some parts of England, used for example by train conductors to passengers. ${ }^{2}$

\section{I.2 Practical applications}

It is obviously of crucial importance to keep the potential differences between address and referential usage in mind when studying the address systems of different languages. The address meaning of a word cannot be assumed to be the same as its referential meaning. From this it follows that we cannot assume that because person A refers to person B with a certain word, A will

[2] The difference between referential and address meaning has been independently investigated by David Allerton (I996), who looks at a different aspect of the issue from that presented here. To the extent that our research overlaps, he and I are in agreement. 
also use that word in addressing $\mathrm{B}$, nor that because $\mathrm{A}$ addresses $\mathrm{B}$ in a certain way, A will also refer to B in that way.

This last is a pitfall into which a number of unwary scholars have fallen (for example, Phillipps 1984: I43-I67). It is not entirely inexcusable, for at first glance it seems reasonable that someone who refers to a friend as Mrs. Smith would also address her as Mrs. Smith. Yet such is not in fact always the case, for a woman who says to her small child, 'Mrs. Smith is coming to dinner, and I want you to try very hard to be polite' may very well address Mrs. Smith as Jane. A pragmatic study of the actual relationship between forms of address and forms of reference is thus in order.

Such a study will not only be useful from the point of view of pragmatics, but will also provide practical assistance to scholars working with a limited amount of data, such as historical linguists. These researchers are often tempted to extrapolate from referential to address usage when this is the only way to arrive at the address usage; some guidelines on when such extrapolation is justifiable and when it is not would prevent much unfortunate speculation. This paper is meant to be a step towards the provision of such guidelines, by a systematic examination of the way in which referential and vocative usages are related. Before discussion of the data, however, one more point must be clarified.

\section{I.3 Referential and etymological meaning}

According to the definition given above, referential meaning is determined by the way that a word is currently used in non-address contexts. It is important to distinguish this meaning from a historical or etymological evaluation of a word's implications. Thus English $M r$. is currently used in reference only when attached to names and indicates a certain amount of distance and/or respect; it is certainly historically related to the word master, and many native speakers may see the connection, but the meaning of $M r$. is no longer the same as that of master. This is not a referential/vocative difference, for in fact the meaning of $M r$. is not greatly different in 'Mr. Smith, would you mind if I closed the window?' from that in 'Mr. Smith had no objection to my closing the window.' It is a diachronic difference.

The same can be said of French monsieur, which once meant 'my lord' but no longer carries this sense in either referential or vocative usage. There is however the difference that monsieur, unlike $M r$., can be used without the addition of a name, as in 'Bonjour, monsieur' or 'Je ne connais pas ce monsieur'. German Herr can also be used alone, but this word retains its original connotations of real deference when so used, whether in address or in reference. The main difference in meaning for Herr seems to lie in whether it is used alone or with a name, not in a current/etymological or vocative/referential distinction. 


\section{ELEANOR DICKEY}

Given the above, it is perhaps unfortunate that $M r$./Mrs. equivalents are not infrequently cited as good examples of the way the meaning of a word used as an address can differ from its 'literal meaning' (for example, Braun I $988: 307-8)$. It seems that if one wants to investigate the connection between referential and vocative meaning, one must restrict one's data to cases in which the word in question occurs, synchronically, in the same form in both situations; we cannot compare Mr. Smith with master, Herr Braun with $H e r r$, or the current meaning of monsieur with that in force several centuries ago.

\section{EXPERIMENTATION}

The relationship between referential and vocative usage is not completely transparent and cannot easily be determined by introspection. It was thus necessary to collect some data on this point, and so I conducted an investigation of the patterns of usage of some American and European students and academics. The resulting data have sometimes been mistaken for an investigation of the changing address habits notable in English of the past few decades. It is to be emphasized that the question of the changes in forms of address is very different from and much more complex than the issue I am addressing, namely the synchronic relationship between address and reference; the first is a historical question and the second a pragmatic one. A different study using a much larger and more diverse group of informants would have to be undertaken in order to provide data on the historical question.

\section{I Procedure for collection of data}

Much of the data was accumulated by observation conducted over the course of two years. It was felt, however, that it would be advantageous to have access to types of data which could not easily be collected in this way (such as family interaction within families other than that of the researcher). For this purpose questionnaire-based interviews were used. The dangers of both questionnaires and interviews are well known (Wolfson I976, Dale 1978), but great efforts were made to reduce the difference between actual usage and reported usage. Several different types of questionnaire and interview were devised, and their results were tested against the observed behaviour of the individual informants.

In the initial stages serious discrepancies were observable between questionnaire and observation data, discrepancies which seemed to be due to the following factors: the length of the questionnaire, the confusing nature of the questions, the apparently repetitive nature of the questions (which led interviewees to repeat the same answer mechanically even when they came to a question to which it did not apply), and discomfort with the questionnaire and interview genres. Later versions of the questionnaire and interview 
addressed these problems, and the final version appeared to remedy all of them successfully, so that very few discrepancies could be found between the informants' observed and reported behaviour. Each version was tested on a different set of informants, in order to be sure that the improvement was not due to the informants' simply working out what was wanted and providing it. Data presented here is taken only from the final version.

It was however necessary to make the interview process less than ideal from the researcher's point of view in order to produce this result. Interviews were short, informal, unscheduled, and took place on neutral territory. They were terminated at once when informants became restless. On balance, it seemed much better to gain in this way a smaller amount of accurate data than to acquire a much larger amount of inaccurate information by using a longer and more detailed questionnaire.

One of the results of this procedure, however, was that not all questions could be asked of each informant, and thus as soon as it became clear that an overwhelming majority of speakers from a given group would answer a certain question in a predictable way, that question was omitted in favor of one to which the answers were less predictable. Much more data has thus been gathered on some questions than on others, and in consequence the results do not lend themselves to statistical analysis.

A total of 28 informants (I I male, I 7 female) were interviewed, between them providing data on 387 interactions. Informants ranged in age from 20 to 75. Most were native speakers of English (I3 British, 8 American), but other languages were also represented: German (2), Italian (I), Czech (I), Welsh (I), Swiss German (I, bilingual with British English), Greek (I, bilingual with American English). Obviously these numbers are not sufficient to enable us to draw conclusions about usage in each language, but they should make it possible for us to see whether English differs radically from these other languages on the points studied. Data from observation was taken from Britain and America only; the data on family interaction contains more American evidence, and that on academic usage is slanted towards Britain, but each country is well represented in both areas.

\subsection{Limits of experiment}

The number of different ways in which a person can be referred to are virtually infinite. It would be ridiculous to attempt to decide how a given person is 'normally' referred to, just as it would be pointless to try to find the 'normal' way in which that person is addressed. Both address and reference vary according to the speaker and express the speaker's relationship to the addressee or person referred to. Each person will normally receive a range of addresses according to the speaker, and it is even possible for the same address to have different implications when used by different people. This phenomenon has been most often studied in the case of pronominal address, 


\section{ELEANOR DICKEY}

where a $\mathrm{T}$ pronoun (for example, French $t u$, German $d u$ ) may convey intimacy when used to the speaker's parents and something very different when used to a domestic servant.

It is therefore important to investigate the relationship of vocative to referential usage within each individual dyad, not in general. It is of no use to find that A addresses B as Mr. Smith and C refers to B as John, if we do not know how A refers to B and $\mathrm{C}$ addresses him. Thus no data have been included for situations in which it was not possible to determine both referential and vocative usage for the dyad concerned.

So far we have spoken as though only one form of address could be used within a given dyad. Such is clearly not the case; the value of addresses such as insults lies in the fact that they are not the normal forms for a given dyad, but rather 'marked', unusual addresses which can be used to convey a particular emotion. Ideally a study such as this one would examine all marked as well as unmarked terms of address, but such examination would greatly increase the scale of the project and is thus inappropriate at this stage. The data on address usage have therefore been restricted to unmarked forms of address. This does not mean that only one form of address has been recorded for each dyad, for it is perfectly possible for factors of setting or audience to make one address form unmarked in certain situations and another unmarked in other situations. Such factors have been recorded where they occurred with sufficient frequency to ensure that no one form of address was general in a given dyad. (The chief example of this phenomenon in our data was teachers who addressed their students one way in formal settings and another way in informal interaction.)

Another problem is that when speakers refer to people unknown to their addressees, the terms used in reference will be governed by the need to convey certain information. In those situations words are commonly used in reference which rarely or never occur in address, as my mother, Dora's husband, James' tutor, the man who owns the grocery store on the corner, etc. The use of these terms is dependent upon factors other than the relationship of vocative and referential usage, and no linguist has so far been misled into believing that such references imply equivalent addresses. They are thus peripheral to our study and in consequence have been eliminated from the data by ensuring that the examples given were ones in which all participants knew one another fairly well and all were members of the community (family or academic) under investigation.

\section{Results of the EXPERIMENTS}

The data concerned two types of interaction, that among family members and that among students and faculty in academic institutions. Data on interactions involving non-academic university staff were also collected but were later discarded as being too incomplete to allow for generalizations. 


\section{I Family interaction}

Within families the main divisions in usage appeared to follow generational lines. Family members of a younger generation than the speaker were almost always addressed by first name (FN), a nickname, or a term of endearment. Reference to younger family members was also by FN (or nicknames), regardless of the person to whom the speaker was talking at the time the reference was made. It appeared that nicknames used in address were also employed in reference by the same speakers, but the data on this point were not extensive. It was also possible for parents to have names for young children which did not occur in address and were used only between the parents. Such names were generally unflattering. Only one other type of reference emerged, from an informant who reported that she sometimes referred to her two older children as brother and sister (not your brother or your sister) when speaking to the youngest child. She did not use these terms when speaking to the older children about their younger sibling.

Family members of the same generation as the speaker were also addressed with FN, nicknames, or (in the case of spouses) terms of endearment. Terms of endearment were virtually never used in reference, even when they were standard in address. Same-generation relatives were normally referred to with FN by speakers addressing members of their own or ascending generations, but with kinship terms by speakers addressing members of younger generations. The kinship term used was that with which the younger family member would have addressed the referent. In the case of addressees who were children, this adaption to the addressee's name for the referent was virtually universal; in the case of adult addressees it was common but admitted of a number of exceptions. Upon investigation of those exceptions it usually transpired that forms of reference used towards that addressee had been different when he or she was a child. In families where children addressed their elders by $\mathrm{FN}$, no such adaption to the viewpoint of the addressee in reference was possible, and parents referred to each other by name when speaking to children. Such families, however, were rare among the observation data and absent from the interview data.

Family members of ascending generations were normally addressed with kinship terms. (The term 'kinship term' here, as generally in address research, includes words such as Mum and Dad as well as mother, father, etc.)

Speakers referred to these family members with kinship terms as well; in talking to members of the same or older generations they generally used the same kinship terms in reference as they would have used to address the older family member, but in talking to members of younger generations they tended to use the kinship term by which the younger relative would have addressed the referent.

There was, however, some individual variation in this category. Although virtually all the informants addressed their parents with kinship terms, these 


\section{ELEANOR DICKEY}

terms were sometimes avoided or modified in reference, especially in families with an unusual structure resulting from divorce or other causes. Thus it was not uncommon for children of divorced parents to use different sets of terminology in the different halves of their families and to employ in conversation with family members terms such as my mother (kinship terms with possessive modifiers), which in most families were restricted to conversations with outsiders. Children in such families were also likely to refer to parents by name despite using kinship terms in address.

One informant maintained that in her family, which included children of four different parents, there was a consistent system of address and reference whereby each child addressed his or her genetic parents with kinship terms and step-parents with FN; step-parents were referred to by name at all times, while genetic parents were referred to with kinship terms to addressees for whom these were also the genetic and/or acting parents and with FN or terms such as my mother when the referent had no real connection with the addressee. Another informant addressed her father with kinship terms and referred to him in the same way within the family in which she had grown up; when talking to his children by another marriage, however, she used $m y$ father or our father. A third informant spoke one language to her mother and another to her father; she used kinship terms in one language to address her mother and kinship terms in another language to refer to her mother when talking to her father.

Despite these variations, the general tendencies of family address were clear; they are summarized in Table I. ${ }^{3}$

\begin{tabular}{||l|l|l|l|l||}
\hline \hline $\begin{array}{l}\text { Relationship } \\
\text { between A } \\
\text { and C }\end{array}$ & $\begin{array}{l}\text { Address } \\
\text { used } \\
\text { from A } \\
\text { to C }\end{array}$ & $\begin{array}{l}\text { Form of } \\
\text { reference used } \\
\text { by A for C in } \\
\text { talking to B }\end{array}$ & $\begin{array}{l}\text { Relationship } \\
\text { between A and B }\end{array}$ & $\begin{array}{l}\text { Relationship } \\
\text { between B and C }\end{array}$ \\
\hline A > C & FN & FN & $\begin{array}{l}\mathrm{A}=\mathrm{B}, \mathrm{A}>\mathrm{B}, \\
\mathrm{A}<\mathrm{B}\end{array}$ & $\begin{array}{l}\mathrm{B}=\mathrm{C}, \mathrm{B}>\mathrm{C}, \\
\mathrm{B}>\mathrm{C}\end{array}$ \\
\hline $\mathrm{A}=\mathrm{C}$ & FN & FN & $\mathrm{A}=\mathrm{B}, \mathrm{A}<\mathrm{B}$ & $\mathrm{B}=\mathrm{C}, \mathrm{B}>\mathrm{C}$ \\
\cline { 2 - 5 } & KT 2 & KT 1 & $\mathrm{A}>\mathrm{B}$ & $\mathrm{B}=\mathrm{B}, \mathrm{A}<\mathrm{B}$ \\
\hline $\mathrm{A}<\mathrm{C}$ & KT & $\begin{array}{l}\mathrm{B}=\mathrm{C}, \mathrm{B}>\mathrm{C}, \\
\mathrm{B}>\mathrm{C}\end{array}$ \\
\cline { 2 - 5 } & & $\mathrm{KT} 2$ & $\mathrm{~B}>\mathrm{B}$ & $\mathrm{B}$ \\
\hline
\end{tabular}

Table 1

Family interaction

[3] In this table and the following one, A is used for the speaker, B for the person to whom $\mathrm{A}$ is speaking, and $\mathrm{C}$ for the person about whom A is speaking. The sign $\mathrm{KT} \mathrm{I}$ is used for the kinship term by which A addresses C; KT 2 is used for the kinship term by which B addresses $\mathrm{C}$. The sign $=$ indicates that both parties are members of the same generation; $<$ and $>$ indicate generational differences. 
In other words, family members were addressed and referred to in the same way, except in conversations with a relative of a younger generation. In those cases the term used in reference was generally that which the younger member of the dyad would have employed in address.

Although informants from different countries obviously differed in specific terms used, there was a high degree of agreement on the general principle that the same term would be used in reference as in address unless the speaker was talking to members of younger generations about their elders. The age of the informants did not seem to make a difference either, indicating that this princple has remained stable for some time.

\subsection{Academic interaction}

The important dimension in the academic setting was not that of age but of position in the academic hierarchy, with the basic division being one of teacher and student. This division was somewhat complicated by the fact that graduate students could function in both roles, but in most situations graduates usually operated as one or the other.

Most teachers used FN in addressing their students, regardless of whether the teachers were graduate students or senior faculty members or of whether the students were graduate or undergraduate. The exceptions were a few older faculty members in both Britain and America who reported using title and last name (TLN) to students, at least until a personal acquaintance was established. A number of British faculty members used TLN to all students in particularly formal settings, such as meetings with administrative officials, and those teachers who normally used TLN to students often switched to FN in informal settings or casual encounters in which they were not actively engaged in teaching the student.

In reference three main possibilities emerged: FN, TLN and a combination of first and last name (FNLN). The last of these was often used in cases where there might be doubt as to the identity of the student under discussion; such cases do not properly belong to the subject of this study, but they occur very frequently in real life and so had a tendency to appear in the data despite all efforts to eliminate them. This fact indicates something also borne out by observation, namely that FNLN for clarity may be used out of sheer habit even in situations in which the identity of the student is clear. These instances are to be distinguished from the use of FNLN as a compromise between FN and TLN, discussed below.

Otherwise, FN was the most common way for teachers to refer to students, whether in speaking to colleagues, superiors, or other students. Teachers who normally addressed students with TLN, however, had a tendency to refer to them with TLN as well, and situations which were formal enough to require the use of TLN in address usually required it in reference too. This 


\section{ELEANOR DICKEY}

convergence between address and reference, however, was not complete, for FNLN could be used as an intermediate level between FN and TLN in reference, being more formal than FN and less formal than TLN.

In a few instances teachers reported having nicknames for some of their students, as little Jimmy, the agent of Satan or le président. ${ }^{4}$ These nicknames were not used to address the students and were generally used only in talking to colleagues about them. In one case, however, a graduate student and her faculty advisor shared their nicknames for undergraduates. Such nicknames were rare (although it is possible that they could have been under-reported in the interviews) and applied only to students who caused the teacher particular stress or suffering.

Graduate students provided a special case of name usage. If a senior faculty member talked about a graduate student to an undergraduate who would not be able to address that graduate with FN, TLN or FNLN was used.

People of the same academic status as the speaker (colleagues or fellowstudents) normally received FN in address. Nicknames were however possible between close friends, and TLN occurred in certain formal settings and sometimes in Britain between distant acquaintances at more senior levels. When talking to people of higher academic status about friends or colleagues, speakers generally used FN in reference, but FNLN was also common, again because it was perceived to be more formal than FN. TLN was used in some especially formal settings, such as large meetings of academic or administrative bodies.

When speaker, addressee, and referent were all at the same academic level, FN was generally used in reference, but TLN and nicknames were also possible, particularly if these were the ways in which the speaker normally addressed the referent. The use of nicknames was somewhat restricted, for a close friend addressed with a nickname would often be referred to with FN to someone who did not have the option of using that nickname. TLN would be used in situations formal enough to require the use of TLN in address.

There were also a number of alternatives to names in this case. A particularly British form of reference was the referent's initials (used in oral as well as written communication), but it was also possible to use a title with a definite article and without the name of the referent (for example, the vicechancellor), as well as individual nicknames. These alternatives seemed to be more frequent in Britain than in America, but in both countries they were less common than FN.

When talking about colleagues to students, teachers tended to use the names by which the students would be expected to address those colleagues, usually TLN. This tendency was stronger in the case of undergraduate than

[4] To protect the confidentiality of informants, these examples have been slightly altered. 
of graduate students; several informants referred to their colleagues with TLN to undergraduates and with FN to graduates, despite the fact that the graduates concerned addressed those colleagues with TLN. Other informants, however, indicated that they made a conscious effort to remember the way that a particular student addressed a particular colleague and to use that name when talking to that student.

Some teachers employed FNLN when talking to students about a colleague whom the students would be expected to address with TLN. These informants commented that they considered FNLN a compromise, since FN was too informal and TLN too awkward. The 'awkwardness' of reference to colleagues with TLN was felt especially by very young teachers who were having to refer to their friends by TLN for the first time; these teachers often used inconsistent patterns of address, feeling that they should employ TLN but then forgetting and using FN instead.

Students addressing teachers could use either FN or TLN, depending on the status of the teacher (graduate student teachers were more likely than distinguished professors to be addressed with FN), the level of the student (graduate students were much more likely than undergraduates to use $\mathrm{FN}$ ), institutional and departmental norms, and individual preferences on the part of both teacher and student. Norms of address were more variable on this point than on others, and usage in reference was even more diverse than that in address.

When talking to faculty members, students most often referred to other teachers with FN or TLN, but FNLN was not infrequent, both from students who used TLN in address and from those who used FN. In the case of FN and TLN there was a general tendency for students to use the same terms in reference as in address, but this tendency was less strong than in the other cases we have so far observed. Occasionally students conversing with faculty members used FN to refer to teachers whom they addressed with TLN, and this appeared to be due to the fact that the addressee was referring to those teachers with FN.

Only the graduate students were in the position of talking about a referent of higher status to an addressee of lower status. Here there was a strong tendency to use TLN (or, less often, FNLN) in reference, regardless of the form of address. In cases where all members of the academic community addressed the faculty member concerned with FN, FN was used in reference as well.

In talking to addressees of equal status about referents of higher status, speakers used a large variety of terms. FN was prevalent in the case of speakers who used FN to address the referent, and TLN was common in the case of speakers who used TLN to address the referent, but nicknames and FNLN were also frequent. Nicknames and FN were used both by students who employed TLN in address and by those who employed FN. There was a higher percentage of nicknames here than in any other category of 


\section{ELEANOR DICKEY}

reference, and one notable feature was the way that one student could have as many as four or five different ways of referring to a single faculty member. Sometimes these terms were interchangeable, sometimes they depended on the addressee, and sometimes they depended on the level of animosity felt by the student towards the faculty member at a given moment. Nicknames were by no means always unflattering.

Tension could be observed in situations where one member of a student dyad addressed a faculty member with FN and the other used TLN; often this was resolved by the student who used TLN in address switching to FN in reference. On the other hand one informant reported using TLN to refer to a faculty member whom she addressed with $\mathrm{FN}$; she ascribed the reason for this usage partly to habit (she had only recently shifted to using FN to address the referent) and partly to a desire to avoid annoying her friends, who did not have the privilege of using FN, by flaunting it.

Despite the multitude of different usages, there were certain general tendencies of academic address, which are summarized in Table $2 .{ }^{5}$

\begin{tabular}{|c|c|c|c|c|}
\hline $\begin{array}{l}\text { Relationship } \\
\text { between A } \\
\text { and C }\end{array}$ & $\begin{array}{l}\text { Address } \\
\text { used } \\
\text { from A } \\
\text { to C }\end{array}$ & $\begin{array}{l}\text { Form of } \\
\text { reference used } \\
\text { by A for C in } \\
\text { talking to B }\end{array}$ & $\begin{array}{l}\text { Relationship } \\
\text { between A and B }\end{array}$ & $\begin{array}{l}\text { Relationship } \\
\text { between B } \\
\text { and C }\end{array}$ \\
\hline \multirow[t]{2}{*}{$A>C$} & \multirow[t]{2}{*}{ FN } & FN & $\mathrm{A}=\mathrm{B}, \mathrm{A}<\mathrm{B}$ & $\mathrm{B}=\mathrm{C}, \mathrm{B}>\mathrm{C}$, \\
\hline & & TLN / FNLN & $\mathrm{A}>\mathrm{B}$ & $\mathrm{B}>\mathrm{C}$ \\
\hline \multirow[t]{2}{*}{$A=C$} & \multirow[t]{2}{*}{ FN } & $\mathrm{FN}$ & $\mathrm{A}=\mathrm{B}, \mathrm{A}<\mathrm{B}$ & $\mathrm{B}=\mathrm{C}, \mathrm{B}>\mathrm{C}$ \\
\hline & & TLN / FNLN & $A>B$ & $\mathrm{~B}<\mathrm{C}$ \\
\hline \multirow[t]{6}{*}{$\mathrm{A}<\mathrm{C}$} & \multirow[t]{3}{*}{ FN } & FN / FNLN & $\mathrm{A}<\mathrm{B}$ & $\mathrm{B}=\mathrm{C}, \mathrm{B}>\mathrm{C}$, \\
\hline & & TLN & $A>B$ & $\mathrm{~B}<\mathrm{C}$ \\
\hline & & FN / FNLN / NN & $A=B$ & $\mathrm{~B}<\mathrm{C}$ \\
\hline & \multirow[t]{3}{*}{ TLN } & TLN / FNLN / FN & $\mathrm{A}<\mathrm{B}$ & $\mathrm{B}=\mathrm{C}, \mathrm{B}>\mathrm{C}$ \\
\hline & & TLN & $A>B$ & $\mathrm{~B}<\mathrm{C}$ \\
\hline & & $\begin{array}{l}\text { FN / FNLN / } \\
\text { TLN / NN }\end{array}$ & $\mathrm{A}=\mathrm{B}$ & $\mathrm{B}<\mathrm{C}$ \\
\hline
\end{tabular}

Table 2

Academic interaction

It thus appears that the prevailing usage among all members of the academic community was to refer to people in the same way that they addressed them, unless they took in reference the perspective of an addressee of lower status. Exceptions to this tendency generally involved nicknames which were used behind the referent's back or an adjustment towards the form of reference used by the other member of a dyad. The tendency to take

[5] Here the notation A $>$ B indicates that A is B's teacher, A $<$ B indicates that A is B's student, and $\mathrm{A}=\mathrm{B}$ indicates that $\mathrm{A}$ and $\mathrm{B}$ have roughly equal academic status. NN stands for nicknames. 
the perspective of addressees of lower status parallels closely the similar tendency in family interaction.

One possible form of reference which appeared very rarely in the interview data was the last name alone, without a title, as Smith or Jones (LN). Observation showed that this type of reference was used primarily for men rather than women and could be applied to superiors, inferiors or equals. In most contexts, however, its use characterised the speaker as coming from a certain type of elite background, and for many speakers the issue of whether or not they wished to signal membership in that type of society appeared to be a primary factor governing the usage of this term. The data collected on $\mathrm{LN}$ usage in this experiment are insufficient to do justice to this phenomenon, but it would amply reward further study.

Nicknames were more noticeable in academic than in family interaction and came in three varieties: those used primarily in address, those used only in reference, and those used generally. The first type of nickname indicated intimacy between speaker and addressee, an intimacy not shared by those speakers who did not have the right to use the nickname; it was normally used in reference only between speakers both of whom shared the right to use it as an address. The third type replaced FN within the community and carried no meaning distinguishable from that of $\mathrm{FN}$ address for other people; this type of nickname also occurred within the family.

The second type was generally used among close associates to refer to a person fairly important in their lives, whether because of that person's power over them (nicknames were used more for powerful superiors than for others) or because of the trouble that person caused them (nicknames for students were virtually restricted to ones who caused teachers distress). Parents' alternative names for young children are probably to be put in this category as well. Nicknames appeared to be more common in academic than in family interaction, but they were consistently under-reported in interviews ('Are you going to tell her what I call her?' was a common query), and it may be that the smaller amount of observation data on family interaction has distorted the evidence on this point.

Nicknames which were diminutives of $\mathrm{FN}$, as Julie or Jimmy, could function as any one of the three types and were the sort of nickname most likely to replace FN altogether in the community. Nicknames bearing less relationship to the person's name, such as Juno, Himself, or the fish ${ }^{6}{ }^{6}$ were more likely to belong to the first or second type.

As in the case of family interaction, academic interaction did not show fundamental differences in different countries. Certain forms were more likely to occur in certain places, and some were apparently unique to a particular location, but the general principles for when reference forms

[6] To protect the confidentiality of informants, these examples have been slightly altered. 


\section{ELEANOR DICKEY}

differed from address forms and when they remained the same were remarkably consistent. The same was true of variation due to age; while some older informants reported having as students used more TLN and less FN to superiors than was the norm among current students, there was no difference in the way that the reference forms of older and younger speakers related to their address forms.

\section{Conclusions}

Data from two widely different types of interaction have produced very similar results. In both spheres there is a close relationship between the way that person $\mathrm{A}$ addresses person $\mathrm{C}$ and the way that $\mathrm{A}$ refers to $\mathrm{C}$. The two forms will generally be the same, and when they differ, this difference will depend on the person to whom the speaker is talking at the time he or she mentions the referent. Specific factors likely to cause differences are:

I. In talking to people of lower status/age (students, children) about their elders/superiors, most speakers use in reference the term which their addressee would use in address to the referent.

2. In talking about an intimate acquaintance to people on less intimate terms with the referent and/or speaker, speakers avoid the use of nicknames or other intimate terms for the referent.

3. In talking to close associates about a referent having considerable power over and/or causing substantial trouble to both speaker and addressee (small children to parents, teachers to students, students to teachers), speakers sometimes use nicknames which are avoided in address.

4. In talking to a superior, speakers sometimes use that superior's forms of reference.

The first two of these could be linked to 'solidarity' and the second two to 'power', if one wishes to interpret the results in terms of the theories of Brown \& Gilman (1960).

\section{I Relationship to previous findings}

Three previous studies have an obvious connection to these results. The first is Luong's (1990) work on Vietnamese terms of reference. Luong observes that in Vietnamese it is very common to address and refer to relatives from the perspective of a younger family member. Thus a woman not only refers to her husband as father when talking to her child but also addresses him as father in the child's presence, and the eldest of three siblings refers to the 
middle sibling as elder brother when talking to the youngest one. It is not however possible to take the perspective of an older family member in either address or reference (Luong I990: 57).

This system is certainly not identical with that found in our survey; while one informant did sometimes address her husband as Daddy in the presence of her small child, such behaviour is far from universal in English and does not apply to siblings. It is nevertheless notable that, as far as terms of reference go, Vietnamese seems to share with English the tendency for older speakers to take the perspective of younger addressees. This tendency is apparently more extensive in Vietnamese than in English, but the difference is one of degree rather than principle, so it is possible that the English and the Vietnamese phenomena are caused by the same factors.

Also relevant is the work of Dietrich Hartmann, who studied address and referential usage within a small group of Germans. Hartmann (1972) investigated the relationship between the pronouns ( $d u$ or Sie) which members of this group used to address their colleagues and the names by which they referred to them. This study was followed by one concerned with the relationship between names used in address and in reference (Hartmann I975).

Hartmann's results were notably different from our own. He concluded that the relationship between addressee and person under discussion had no effect on the name used in reference; the crucial factors were the way the speaker addressed the referent and the relationship between speaker and addressee (Hartmann I975: I39).

His results are difficult to assess in many ways. One reason is that German has many more available name variants than English: acceptable forms of reference include not only FN, TLN, and FNLN, but also the use of two titles with a last name and the use of either first or last name with a definite article (for example, the Mary, the Smith) (Hartmann I975: I30). Another is that the situations in which one might expect the speaker to be particularly concerned with the relationship between addressee and referent (that is, where speaker and referent address each other with a $\mathrm{T}$ pronoun, but addressee and referent use a V pronoun) are inexplicably absent from Hartmann's data (Hartmann I972: I29-I30, I975: I32-I38).

A third difficulty is the nature of Hartmann's sample; it consisted of twelve people from one university, ranging in status from a full professor to undergraduate students and a secretary (Hartmann I975: I29), and yet there were no non-reciprocal address patterns (I975: I3I) and all relationships were measured in terms of distance rather than power (I972: 295-296). It is possible that this measurement was unrealistic, and/or that Hartmann's sample was atypical.

German forms of reference have also been studied by Richard Geiger (1979), who explored in more detail the different possibilities for reference which can arise from different degrees of kinship and acquaintance. Geiger's 


\section{ELEANOR DICKEY}

work provides some important insights into the factors governing forms of reference, but he does not really address the issue of how these forms are related to the address forms used in the same dyad.

\subsection{Explanation of results}

The model which best explains our results appears to be accommodation theory. This theory, which was developed in the early 1970's and has grown rapidly in the past twenty years, accounts for the ways in which people alter their speech patterns to fit their addressees and audience. (For a fuller account of the history and principles of accommodation theory, see Giles, Coupland \& Coupland I99I.) Such alteration can take a number of different forms; for example, speakers may bring their speech patterns closer to those of the addressee (convergence), but they may also exaggerate differences in their speech (divergence). Accommodation may also involve shifts in speech style based on non-linguistic characteristics of the addressee.

In some of the examples in our data, convergence appears to be at work. It has been observed that 'the greater the speakers' need to gain another's social approval, the greater the degree of convergence there will be.' (Giles et al. I99 I : 19) This factor will explain the way that students in conversing with teachers sometimes found themselves echoing the teachers' FN references to colleagues whom the students addressed with TLN.

It will also explain why students who have different ways of addressing the same teacher are likely to converge towards the more informal means of reference when discussing that teacher among themselves. The right to address a teacher with FN is considered an honour in all of the academic communities investigated except those in which everyone used this form of address (despite the fact that students in these communities who used FN to teachers were by no means always more advanced, more successful, or personally closer to the teachers than students who used TLN). Since forms of address and reference are so often the same, a student who refers to a teacher with $\mathrm{FN}$ will often be perceived to have, or at least to be pretending to have, more status than one who refers to the same teacher with TLN. In conversation the language of the student with the lower status will converge towards that of the student with higher status. This convergence is more common than that involving faculty members, since it is also fueled by a desire to compete linguistically with the addressee for status.

These examples of convergence, however, were much less common than those in which the person of higher status adopted the mode of reference used by the person of lower status. Such shifts seem at first glance to contradict completely the principles of accommodation. Parents and teachers ought to converge towards children and students much less than the children and students converge towards them. Yet in actual fact adults frequently 
alter their language when addressing very small children; the 'babytalk' that results is distinctive enough to be one of the standard examples of the way that addressee can affect style (see Holmes I992: 246-248). On the other hand, most examples of adults altering their language for children make that language simpler and more casual than the language used to other adults, while in the use of proper names the opposite is true: the woman who exhorts her daughter to be polite to Mrs. Smith may very well ask her husband to move his muddy boots before Jane comes.

In fact, however, it is likely that these examples are a strong proof of the existence of the convergence principle and its general recognition among speakers of English. Children are an extreme example of convergence: in learning to use language at all, they are converging towards the adults around them. And most parents realize that children learn language from the people they hear, so they recognize that a child will only learn to call its father Daddy if its mother teaches it to do so. They thus converge towards what they want the child to produce, in order to get the child to produce it.

The situation regarding teachers and students is apparently different, for university students are old enough to learn language in ways other than by blind imitation. Yet in fact we saw that students did have a tendency to converge towards their teachers' usage, in some cases even when they were trying not to. There was a tension between converging towards the actual usage of the addressee (leading to the use of FN to refer to teachers) and convergence towards the usage the student thought the addressee would want (leading towards the use of TLN for teachers). It is likely that teachers who take the point of view of a student addressee and refer to their colleagues with TLN are deliberately attempting to prevent their addressees converging towards their own usage and producing FN.

The term 'convergence', of course, implies that each person has a standard usage of his or her own and departs from that usage under certain circumstances. Is such an assumption warranted in the case of address forms? Before we answer that question, we should consider whether it is ever warranted. If language is virtually always directed at an addressee, and the identity of the addressee always has some effect on the language, which type of language can one take as 'standard' for a given speaker? In some cases there may be one form which is used much more often than others, or with which the speaker feels more comfortable, but in other cases no such clear priority is evident.

On the whole, address usage was more consistent than reference usage in my data; that is, if A addresses C as Mrs. Smith in one setting, it is highly probable that $\mathrm{A}$ will address $\mathrm{C}$ in the same way in most other settings. It is much less probable that $A$ will always refer to $C$ in the same way, and this suggests that perhaps address usage should be considered the 'normal' form from which convergence is measured. Such a theory is also supported by the fact that when young teachers are first obliged to use TLN to refer to people 


\section{ELEANOR DICKEY}

whom they address with FN, they often report great discomfort about this shift.

On the other hand, another source of discomfort was addresses to people who were frequently referred to by names different from those by which they were addressed. In those circumstances it was possible for the term of reference to be used accidentally in address, a mistake which could cause great embarassment (for example, the use of an unflattering nickname for a superior). Informants were well aware of this danger; one refused to use nicknames for superiors at all out of fear of this result. Such mistakes also indicate that speakers may have a 'normal' word for each other person, from which they deviate as necessary according to the people to whom they are speaking, but they also suggest that in certain circumstances a term of reference rather than of address may be that 'normal' form. It thus seems that it is indeed possible to speak of a base form of address/reference from which convergence occurs, but that one must exercise caution in determining what that base form is.

Can Luong's and Hartmann's results be explained by accommodation theory as well? Although neither author used accommodation theory to explain his results, it may be applicable in both cases. The system of kinship reference which Luong describes is clearly very elaborate and depends on other factors as well as accommodation. Yet it is very likely that it originated in the tendency of adults to take the perspective of small children in referring to older relatives, in order to teach the children how to address those relatives correctly. Hartmann's results seem to be a case of shift in register according to the addressee, a phenomenon accounted for by accommodation theory.

It thus seems that the same factors are at work in determining address and reference usage in German, Vietnamese and English; it is just that these factors operate differently in the different languages. Given that information, we should be able to formulate some guidelines for researchers who need to predict address forms from terms of reference, or vice versa.

\subsection{Guidelines for researchers}

Tentative guidelines for predicting forms of address from forms of reference could be drawn up as follows, using A to indicate the speaker, B the addressee, and $\mathrm{C}$ the referent:

I. The way that $\mathrm{A}$ refers to $\mathrm{C}$ is likely to be the same as the way that $\mathrm{A}$ addresses $\mathrm{C}$, unless some form of accommodation occurs.

2. Accommodation in addressing $\mathrm{C}$ will usually occur if the form of reference 'normal' for $\mathrm{A}$ is one which would offend $\mathrm{C}$ if used in address. This situation is most likely to arise when $\mathrm{C}$ is a person with considerable power over or causing significant annoyance to both $\mathrm{A}$ and $\mathrm{B}$. 
3. Accommodation in referring to $\mathrm{C}$ will depend on $\mathrm{A}$ 's relationship to $\mathrm{B}$ and B's relationship to C. It is least likely to occur when A, B, and C all use the same type of name to address one another, a situation likely to arise if $\mathrm{A}, \mathrm{B}$, and $\mathrm{C}$ are roughly equal in status and there is roughly the same amount of distance between each member of this group. It is most likely to occur when:

a. B's status is greater than A's. (A may converge towards B's usage.)

b. A and C are on familiar terms, but $\mathrm{A}$ and $\mathrm{B}$, and/or B and C, are only distantly acquainted. (A will accommodate in register to eliminate excessively familiar forms from the conversation.)

c. Both $\mathrm{A}$ and $\mathrm{C}$ are of higher status than $\mathrm{B}$, and $\mathrm{A}$ recognizes that $\mathrm{B}$ is likely to converge towards A's usage and wishes to prevent such convergence. (A will converge towards B's usage.)

These guidelines have of course been based on data from a very small number of languages, and they cannot be proven to apply to other languages as well. It seems, however, that until counterexamples to these principles are found in another language, reseachers into address forms in that language should refrain from assuming that a form used in reference would also be used in address if these guidelines suggest that it would not be so used.

\section{REFERENCES}

Allerton, D. (1996). Proper names and definite descriptions with the same reference: a pragmatic choice for language users. Journal of Pragmatics 25. $62 \mathrm{I}-633$.

Braun, F. (1988). Terms of address: problems of patterns and usage in various languages and cultures. Berlin: Mouton de Gruyter.

Brown, R. \& Ford, M. (196I). Address in American English. Journal of Abnormal and Social Psychology 62. 375-385.

Brown, R. \& Gilman, A. (1960). The pronouns of power and solidarity. In Sebeok, T. A. (ed.). Style in language. London: Wiley \& Sons. 253-276.

Dale, I. R. H. (I978). Beyond intuition: the use of questionnaires in linguistic investigation. Anthropological Linguisitics 20. I $58-\mathrm{I} 66$.

Geiger, R. A. (1979). Third-person reference in German. Papers in Linguisitics: International Journal of Human Communication $\mathbf{I 2}\left(\mathbf{3}^{-4}\right) .535-552$.

Giles, H., Coupland, J. \& Coupland, N. (I99I). Accommodation theory: communication, context and consequence. In Giles, H., Coupland, J. \& Coupland, N. (eds.). Contexts of accommodation: developments in applied sociolinguistics. Cambridge: Cambridge University Press. I-68.

Hartmann, D. (1972). Der Gebrauch von Namen und Personen-bezeichnungen als Ausdruck sozialer Beziehungen in einer Kleingruppe. In Hyldgaard-Jensen, K. (ed.). Linguistik: Referate des 6. linguistischen Kolloquiums II.-I4. August I97I in Kopenhagen. Frankfurt am Main: Athenaeum. 285-306.

Hartmann, D. (I975). Thesen zum Gebrauch von Anredeformen und Bezeichnungen dritter Personen in der direkten Kommunikation. In Jäger, S. (ed.). Probleme der Soziolinguisitk. Göttingen: Vandenhoeck \& Ruprecht. I I I-I 42.

Holmes, J. (I992) An introduction to sociolinguistics. London: Longman.

Luong, H. V. (1990). Discursive practices and linguistic meanings: the Vietnamese system of person reference. Amsterdam: John Benjamins.

Phillipps, K. C. (I984). Language and class in Victorian England. Oxford: Basil Blackwell.

Wolfson, N. (1976). Speech events and natural speech: some implications for sociolinguistic methodology. Language in Society 5. I89-209. 


\section{ELEANOR DICKEY}

Zwicky, A. M. (1974). Hey, Whatsyourname! In La Galy, M. W., Fox, R. A. \& Bruck, A. (eds.). Papers from the Tenth Regional Meeting of the Chicago Linguistic Society. Chicago: Chicago Linguistic Society. 787-80I.

Author's address: Department of Classics and Religious Studies,

University of Ottawa,

P.O. Box 450, Stn. A,

70 Laurier Avenue East,

Ottawa, Ontario, KIN $6 N_{5}$,

Canada.

E-mail:edickey@aixI.uottawa.ca 